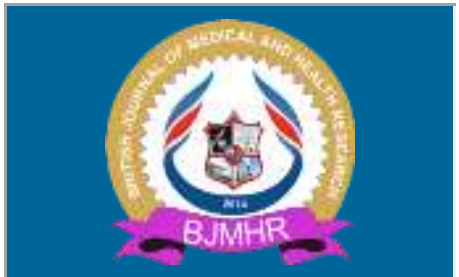

\title{
BJMHR
}

British Journal of Medical and Health Research Journal home page: www.bjmhr.com

\section{Pregnancy Outcome of Multiple Gestation at the University of Port Harcourt Teaching Hospital, Nigeria: A 5-Year Review.}

\author{
Justina Omoikhefe Alegbeleye*, Kemebradikumo Kelvin Edonkumoh \\ Department of Obstertrics and Gynaecology, University of Port Harcourt Teaching \\ Hospital, Port Harcourt, Rivers State
}

\section{ABSTRACT}

Multiple pregnancies are considered as high-risk pregnancies due to the increased associated maternal and fetal morbidity and mortality. The incidence of multiple pregnancy varies from region to region, with a very high incidence recorded in Nigeria and other African countries. The aim of this study was to determine the prevalence and the feto-maternal outcome of multiple pregnancies. This was a retrospective study of all pregnant women who had multiple gestation at the University of Port Harcourt Teaching Hospital from January 1, 2012 to December 31, 2016. Data was obtained from the case notes and the special care baby unit (SCBU). The data obtained was entered into a spread sheet and analyzed using SPSS 22. Results are presented in simple percentages and tables. The $\mathrm{P}$ value was set at $<0.05$. During the period under review there were 9,895 deliveries, of which 287 were multiple pregnancies, giving a multiple pregnancy rate of 29/1000 deliveries. The mean age of the women was 29.0 \pm 4.3 years, while the mean parity was $1.6 \pm 1.5$. Majority $(85 \%)$ of the pregnancies were achieved spontaneously, while $15 \%$ were achieved through assisted reproductive technology. Twin pregnancies made up $92.1 \%$ of multiple gestations. The most common antenatal complication was pregnancy induced hypertension (22\%). The caesarean section rate was $71 \%$, the most common indication for caesarean section was abnormal lie and presentation of the leading twin $(26.3 \%)$. About half $(53 \%)$ of the babies were delivered preterm, with a mean gestational age at delivery of $35.1 \pm 1.5$ weeks. Of the 558 babies delivered, $52.3 \%$ had low birth weight. There were 43 perinatal deaths, giving a perinatal mortality rate of 77/1000 total births. Perinatal mortality was significantly associated with prematurity (0.0001) and booking status (0.0001). There were three maternal deaths, giving a maternal mortality ratio of 556.04/ 100,000 live births. All the maternal deaths were in unbooked patients. Multiple pregnancy is a high-risk pregnancy, associated with a high rate of perinatal and maternal morbidity and mortality. It is recommended that women with multiple pregnancy should have supervised antenatal care and delivery in a facility with good obstetric and neonatal intensive care services.

Keywords: Multiple pregnancy, feto-maternal outcome, Port Harcourt, Nigeria

*Corresponding Author Email: drefe_2@yahoo.co.uk

Received 05 March 2020, Accepted 22 March 2020

Please cite this article as: Alegbeleye JO et al., Pregnancy Outcome of Multiple Gestation at the University of Port Harcourt Teaching Hospital, Nigeria: A 5-Year Review . British Journal of Medical and Health Research 2020. 


\section{INTRODUCTION}

Multiple pregnancy is a high-risk pregnancy, associated with a high maternal and perinatal morbidity and mortality. ${ }^{1}$ Multiple pregnancy consists of two or more fetuses, the more the fetuses, the higher the risks of complications. ${ }^{2}$ Majority of multiple pregnancies are twin (9799\%), while the remainder is mainly triplet pregnancies. 3,4

The incidence of multiple pregnancy varies from region to region, ${ }^{1,5}$ this variation in incidence are due to factors influencing dizygotic twining which results from multiple ovulation. In contrast, monozygotic twins results from division of a single blastocyst, and occurs with a constant incidence of 3.9/1000. ${ }^{1,2,4,5}$ In Nigeria, the incidence of twin pregnancy varies from 28/ 1000 births in the North to 49/1000 births in the West. ${ }^{5}$ The highest rate of spontaneous twin pregnancy in the world is seen amongst the Yoruba ethnic group in the Southwest region of Nigeria, where the rate is as high as $68.1 / 1000$ live birhs. ${ }^{1,4,5}$ In the United kingdom, the rate of multiple pregnancy is $16 / 1000$ live births, the lowest incidence is seen among the Mongoloids with a prevalence of 6.7/ 1000 live births. ${ }^{4}$ The incidence of multiple pregnancies has increased globally over the past three decades especially in the developed countries due to increase in maternal age and increased use of assisted reproductive technology. ${ }^{1,2,5}$ Other factors that tend to influence the occurrence of multiple pregnancies are diet, maternal history of twining, socio-environmental factors, and the use of fertility drugs for induction of ovulation. ${ }^{1-3}$ In the USA and other developed countries, approximately over one-third of twin pregnancies and approximately $80 \%$ of triplet and other higher order pregnancies are achieved following treatment for infertility. ${ }^{4}$

Multiple pregnancies can be classified according to the number of fetuses (twin, triplet, or quadruplet), based on the number of fertilized eggs (zygosity), based on the number of placentae (chorionicity) or based on the number of amniotic cavities (amnionicity). ${ }^{3,4,6}$ Zygosity and chorionicity are very important predictors of perinatal morbidity and mortality, with monochorionic fetuses having a higher risk of perinatal mortality. $3,4,6$

Majority of the obstetric complications aside from prolonged pregnancy and cephalopelvic complications have been shown to be two or more times commoner in multiple pregnancies than in singleton pregnancies. Preterm delivery is one of the commonest and most serious complication of multiple pregnancy, it can either be spontaneous or iatrogenic, due to the occurrence of other pregnancy related complications such as severe preeclampsia or other medical complications which are also more likely to occur in multiple pregnancies than singleton pregnancies, overall about $60 \%$ of twin pregnancies result in spontaneous delivery before 37 weeks. ${ }^{1,3,4}$ The rate of maternal morbidity and mortality are higher in multiple pregnancies than in singleton pregnancies due to the increased occurrence of obstetric 
complications, such as antepartum and postpartum hemorrhage, hypertensive diseases in pregnancy and anaemia. ${ }^{5}$ The perinatal mortality rate of twin and triplet gestation is about 3-5 times and 10 times higher, respectively when compared to singleton gestations due to increased incidence of congenital anomalies, prematurity, hypoxia and birth trauma. The commonest cause of perinatal death is prematurity. ${ }^{1,3,4,7}$

Due to increasing incidence of multiple pregnancies globally and the higher risk of maternal and perinatal morbidity and mortality associated with it, this study was carried out to evaluate the incidence of multiple pregnancy at the University of Port Harcourt teaching hospital, and the associated maternal and perinatal complications.

\section{MATERIALS AND METHOD}

\section{Study site}

This study was carried out at the labour ward and special care baby unit of the University of Port Harcourt Teaching Hospital. The University of Port Harcourt Teaching Hospital is a 882bed tertiary hospital located at Alakahia in Obio Akpor Local Government Area of Rivers State, South-South Nigeria. An average of 3000 deliveries are conducted annually. The unit has a total of 153 beds, with 30 beds in the antenatal ward, 40 beds in the postnatal ward, 40 beds in the unbooked ward, 13 beds in the first stage room, 4 beds in the second stage room and 8 beds in the private/semi-private rooms. There are five units, each unit has five consultant obstetricians, five specialist senior registrars and five registrars with many experienced nurses and midwives. There are also pediatricians and anesthetists on call.

\section{Methods}

This was a retrospective study conducted at the University of Port Harcourt Teaching Hospital over a 5-year period, from January 1, 2012 to December 31, 2016. The data was retrieved from the case notes, theatre records, delivery register and from the special care baby unit (SCBU) over the period under review. The variables obtained included age, parity, booking status, antepartum, intrapartum and postpartum complications, mode of delivery, gestational age at delivery and feto-maternal outcomes.

\section{Statistical Analysis}

The proforma for each patient was checked for completion before it was entered into a predesigned spreadsheet. The data was analyzed using Statistical package for social science SPSS 22. The results are presented in simple percentages and tables. $P$ values $<0.05$ were considered statistically significant.

\section{RESULTS AND DISCUSSION}

There were 9895 deliveries during the period under review. Of these, 287 were multiple deliveries, giving an incidence of 29/1000 births. The incidence of multiple delivery was 
29.5/1000 births in booked patients and 26.8/1000births in unbooked patients. However, only 267 case notes were available for analysis. Majority of the patients, $220(82.4 \%)$ were booked. The mean age of the women was $29.04 \pm 4$.3years while the mean parity was $1.6 \pm 1.5$. Almost all pregnancies, 227 (85\%) were conceived spontaneously while only 40 (15\%) were achieved through assisted reproductive techniques. There were $246(92.1 \%)$ twin deliveries, 20 (7.5\%) triplet deliveries and 1(0.4\%) quadruplet delivery. The twin birth rate was $24.5 / 1000$ births, the triplet birth rate was $2 / 1000$ births and quadruplet birth rate was $0.1 / 1000$ births. These are shown in Table 1.

Table 2 shows the complications associated with multiple pregnancies. The most frequent antenatal complication was pregnancy induced hypertension observed in 58 (22\%) patients. The commonest intra partum complication was fetal distress 43(16\%). Postpartum hemorrhage occurred in $28(10.5 \%)$ patients while $20(7.5 \%)$ had puerperal sepsis. About half of the patients $136(51 \%)$ had preterm deliveries. The mean gestational age at delivery is $35.1 \pm 5.1$ weeks. There were 3 maternal deaths, giving a maternal mortality ratio of 556.4/100,000 live births. All maternal deaths occurred in unbooked patients and were due to postpartum hemorrhage. About three-quarter of the patients 190 (71\%) had caesarean section. The indications for caesarean section are shown in Table 3. The most common indications for caesarean section were abnormal lie and presentation of the leading twin $50(26.3 \%)$.

There were 530 (95\%) live babies, 28(5\%) still births, and 15 (2.7\%) early neonatal deaths, with a total of 43 perinatal deaths, giving a perinatal mortality rate of 77/1000 total births. More than half $23(53.4 \%)$ of the cases of perinatal deaths were babies of unbooked women. The unbooked perinatal mortality rate was $240 / 1000$ births, while the booked perinatal mortality rate is $43.3 / 1000$ births. Perinatal mortality was significantly associated with unbooked status (0.0001). There were 296 (53\%) preterm babies. Perinatal mortality was significantly associated with prematurity (0.0001). There were $292(52.3 \%)$ low birth weight babies with a mean birth weight of $2.2 \pm 0.5 \mathrm{~kg}$. Of the 530 (95\%) live babies, 190 (35.8\%) babies were asphyxiated, while 340 (64.2\%) babies had normal APGAR scores at birth, $82(43.2 \%)$ of the babies with birth asphyxia were delivered vaginally, while 108 (56.8\%) were delivered by caesarean section, however this was not statistically significant $(x 2=2.38, p=0.12)$. These are shown in Tables 4 and 5. 
Table 1: Socio-demographic Characteristics

\begin{tabular}{lll}
\hline Variables & Frequency $(\mathbf{N})$ & Percentage (\%) \\
\hline Age & & \\
$<20$ & 4 & 1.5 \\
$21-34$ & 208 & 77.9 \\
$35-40$ & 55 & 20.6 \\
Parity & & \\
Nulliparous & 84 & 31.4 \\
Primiparous & 56 & 21.0 \\
Multiparous & 127 & 47.6 \\
Booking status & & \\
Booked & 220 & 82.4 \\
Unbooked & 47 & 17.6 \\
Type of Multiple Pregnancy & & \\
Twin & 246 & 92.1 \\
Triple & 20 & 7.5 \\
Quadruplet & 1 & 0.4 \\
Total & 267 & 100 \\
\hline
\end{tabular}

Table 2: Maternal Complications

\begin{tabular}{|c|c|c|}
\hline Variables & Frequency $(\mathbf{N})$ & Percentage (\%) \\
\hline \multicolumn{3}{|l|}{ Antepartum } \\
\hline Pregnancy induced hypertension & 58 & 22.0 \\
\hline Preeclampsia & 36 & 13.4 \\
\hline Anaemia in pregnancy & 32 & 12.0 \\
\hline Malaria & 30 & 11.0 \\
\hline Preterm rupture of membranes & 17 & 6.0 \\
\hline Intrauterine fetal death & 14 & 5.0 \\
\hline Antepartum hemorrhage & 7 & 2.6 \\
\hline Eclampsia & 3 & 1.1 \\
\hline \multicolumn{3}{|l|}{ Intrapartum } \\
\hline Fetal distress & 43 & 16.0 \\
\hline Cephalopelvic disproportion & 8 & 3.0 \\
\hline Retained $2^{\text {nd }}$ Twin & 5 & 1.9 \\
\hline \multicolumn{3}{|l|}{ Postpartum } \\
\hline Primary postpartum hemorrhage & 28 & 10.5 \\
\hline Puerperal sepsis & 20 & 7.5 \\
\hline Maternal death & 3 & 1.1 \\
\hline
\end{tabular}

Table 3: Indications for caesarean section

\begin{tabular}{lll}
\hline Variables & Frequency $(\mathbf{N})$ & Percentage (\%) \\
\hline Abnormal lie and presentation & 50 & 26.3 \\
Hypertensive disorders & 45 & 23.7 \\
Fetal distress & 43 & 22.6 \\
Higher order pregnancies & 21 & 11.5 \\
2 or more previous Caesarean section & 16 & 8.4 \\
Cephalopelvic disproportion & 8 & 2.9 \\
Antepartum hemorrhage & 7 & 2.6 \\
Total & 190 & 100 \\
\hline
\end{tabular}


Table 4: Fetal Outcome

\begin{tabular}{llll}
\hline Variables & Booked & Unbooked & Total \\
\hline Total number of babies & 462 & 96 & 558 \\
Number of live babies & 450 & 80 & 530 \\
Number of low birth weight babies & 230 & 62 & 292 \\
Total preterm babies & 254 & 42 & 296 \\
Birth asphyxia & 146 & 44 & 190 \\
Still births & 12 & 16 & 28 \\
Early neonatal deaths & 8 & 7 & 15 \\
Perinatal mortality rate (per 1000 total births) & 43.3 & 240 & 77.1 \\
\hline
\end{tabular}

Table 5: Perinatal Mortality

\begin{tabular}{llll}
\hline Variables & Frequency & X2 & P Value \\
\hline Booked & 20 & & \\
Unbooked & 23 & 39.8 & 0.0001 \\
Normal birth weight & 4 & & \\
Low birth weight & 39 & 23.5 & 0.001 \\
Term & 3 & & \\
Preterm & 40 & 23.7 & 0.001 \\
\hline
\end{tabular}

\section{DISCUSSION}

The primary finding in this study was a high multiple pregnancy rate of 29/1000 births and associated high maternal complications and perinatal mortality. These findings corroborate the already established fact that multiple pregnancy is a high-risk pregnancy and has a huge burden in our environment. The multiple pregnancy rate is similar to rates reported in Bida, Uyo, Kano and Enugu, 1,7,8,9 far higher than those reported in the United Kingdom and other European countries. and other European countries ${ }^{4}$ but lower than reported in the South West of Nigeria. ${ }^{10}$ This is in agreement with findings in the literatures that twining rate is higher among Blacks compared to other races. It also shows that the rate of twining is higher in the Western region of Nigeria where the rate is as high as 64/1000births, ${ }^{10}$ as opposed to $24.5 / 1000$ births in this study. This could be attributed to the high consumption of yam tubers in the West, which have been found to contain some clomiphene-like substance. ${ }^{5}$

Multiple pregnancy have been reported to be common among older women up to mid-thirties, which is presumed to be due to the rise in follicle stimulating hormone concentration as women get older. ${ }^{3,6}$ In contrast, the mean age in this study was $29 \pm 4.3$ years, which is similar to studies done in Bida ${ }^{1}, \mathrm{Uyo}^{7}$ and Illorin. ${ }^{11}$ However, these were all hospital based studies, as such they may not be reflective of the general population.

Three-quarter of the women had antenatal complications, this is not surprising as obstetric complications have been shown to be two or more times commoner in multiple pregnancy. Pregnancy induced hypertension was the most common antenatal complication, this is in agreement with other studies done in Nigeria. ${ }^{1,5}$ However, in a study done at Ile-ife, ${ }^{12}$ preterm rupture of membrane was the commonest complication. Primary postpartum hemorrhage was 
the commonest postpartum complication, several studies have shown that patients with multiple pregnancy are at increased risk for postpartum hemorrhage. ${ }^{3,4,6}$ This is essentially due to over distension of the uterus, multi parity or sequel to antepartum hemorrhage. The three cases of maternal deaths in this study were as a result of complications of postpartum hemorrhage.

The Caesarean section rate in multiple pregnancy is generally about 2-3 times higher than in singleton pregnancy, ${ }^{3,6}$ this is consistent with the very high Caesarean section rate of $71 \%$ in this study. This is expected due to the significant number of antepartum and intrapartum complications observed in the study, as most obstetricians would consider Caesarean delivery when there are two or more high risk conditions in a patient, thus contributing to the high-risk nature of multiple pregnancy. The commonest indications for Caesarean section were abnormal lie and presentation of the leading twin and hypertensive disorders, this is similar to other studies. ${ }^{1,2,5,7,9}$ This could be due to the fact that most obstetricians prefer abdominal delivery when the leading twin is breech, in order to prevent fetal interlocking syndrome and its associated high fetal mortality. However, recent studies have shown that in carefully selected cases there is no statistically significant difference in the neonatal outcome in twin pregnancies with the leading twin being cephalic or breech when delivered vaginally. ${ }^{13,14}$

The high perinatal mortality rate of $77 / 1000$ births in this study buttresses evidence in the literatures that perinatal mortality is 4 to 6 times higher in multiple pregnancies than in singleton pregnancies. Nearly all the cases of perinatal deaths were preterm babies with a mean gestational age at delivery of $34.7 \pm 5.1$ weeks. This is similar to other studies done in Nigeria and Bangladesh. ${ }^{2,5,8,9,15,16}$ The high perinatal mortality rate in unbooked patients as opposed to the booked patients, further emphasizes the need for supervised antenatal care and skilled delivery for women with multiple pregnancy. ${ }^{17,18}$

\section{CONCLUSION}

Multiple pregnancy is a high-risk pregnancy associated with high rate of maternal and perinatal morbidity and mortality. Therefore, it is recommended that women with multiple pregnancy should have supervised antenatal care and delivery in a facility with good obstetric and neonatal intensive care services.

\section{REFERENCES}

1. Adewale FB, Adewale A, Oyetiunji AO. Trends of multiple birth at Federal Medical Centre Bida, Northcentral Nigeria. Trop J Obstet Gynecol 2018; 35 (1): 68-72.

2. Okunade KS, Daramola E, Adenekan M, Sekumade A, Ajepe A, Osanyin GE. Review of twin deliveries and fetomaternal outcomes in a Tertiary Hospital in Lagos, SouthWest Nigeria. Nig J Gen Pract 2018; 16 (1): 6-9. 
3. Bush MC, Pernoll ML. Multiple Gestation. In: DeCherney AH, Nathan L, Laufer N, Roman AS, editors. Current Diagnosis \& Treatment: Obstetrics \& Gynecology. 11th ed. New York: The McGraw-Hill Companies, 2013; 301-309.

4. Fergus M. Multiple pregnancy. In: Kenny LC, Myers JE, editors. Obstetrics by Ten Teachers. $20^{\text {th }}$ ed. Boca Raton: CRC Press, 2017; 105-115.

5. Eka PO, Swende TZ, Ojabo AO, Utoo BT, Silas O, Maanongun MT, Et al. Review of twin deliveries in Makurdi, North-central Nigeria. Int J Sci Res 2018; 7(3) :10-12.

6. Kilby MD, Oepkes D. Multiple Pregnancy. In: Edmonds KD, Christoph L, Tom B, editors. Dewhurst's Textbook of Obstetrics \& Gynaecology. $9^{\text {th }}$ ed. Oxford: WileyBlackwell, 2018; 268-281.

7. Abasiattai AM, Umoiyoho AJ, Utuk NM, Shittu DG. Incidence and mode of delivery of twin pregnancies in Uyo, Nigeria. Nig Med J 2010; 51(4): 170-172.

8. Attah RA, Mohammed Z, Gobir M. A review of twin deliveries in Aminu Kano Teaching Hospital, North-West Nigeria. Nig J Basic Clin Sci 2014; 11(3): 3-7.

9. Nwankwo TO, Aniebe UU, Ezenkwele E, Nwafor MI. Pregnancy outcome and factors affecting vaginal delivery of twins at University of Nigeria Teaching Hospital, Enugu. Nig J Clin Pract 2013; 16(4): 490-495.

10. Olusanya BO. Perinatal Outcomes of Multiple Births in South-West Nigeria. J Health Popul Nutr 2011; 29(6):639-647.

11. Iyiola OA, Oyeyemi FB, Raheem UA, Mark FO. Frequency of twinning in Kwara State, North-Central Nigeria. Egypt J Med Hum Genetics 2013; 14(1):29-35.

12. Kuti O, Owolabi AT, Fasubaa OB. Outcome of twin pregnancies in a Nigerian Teaching Hospital. Trop J Obstet Gynaecol 2006; 23(2):133-136.

13. Steins Bisschop CN, Vogelvang TE, May AM, Schuitemaker NWE. Mode of delivery in non-cephalic presenting twins: a systematic review. Arch Gynecol Obstet 2012 ;286(1):237-247.

14. Bats A-S, Marie V, Sentilhes L, Cabrol D, Goffinet F. First breech twin pregnancy: Can we still accept a vaginal delivery? Comparative study of perinatal outcome with attempt of vaginal delivery versus planned cesarean delivery. J Gynecol Obstet Biol Reprod 2006; 35 (6): 584-593.

15. Akaba GO, Agida TE, Onafowokan O, Offiong RA, Adewole ND. Review of Twin Pregnancies in a Tertiary Hospital in Abuja, Nigeria. J Health Popul Nutr 2013; 31(2):272-277.

16. Sultana M, Khatun S, Saha AK, Akhter P, Shah ABS. Maternal and Perinatal Outcome of Twin Pregnancy in a Tertiary Hospital. Ibrahim Card Med J 2013; 1(2):35-39. 
17. Kana MA, Doctor HV, Peleteiro B, Lunet N, Barros H. Maternal and child health interventions in Nigeria: a systematic review of published studies from 1990 to 2014. BMC Public Health 2015; 15:334.

18. Luke B, Brown MB, Misiunas R, Anderson E, Nugent C, van de Ven C, Et al. Specialized prenatal care and maternal and infant outcomes in twin pregnancy. Am $\mathbf{J}$ Obstet Gynecol 2003;189 (4): 934-938.

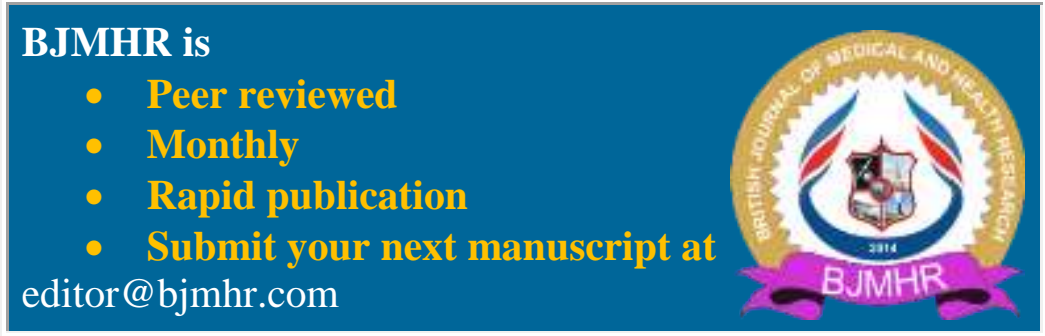

